\title{
ADMINISTRATIVE DIVISIONS WITHIN THE NATIONAL HEALTH SERVICE
}

\author{
BY \\ A. LESLIE BANKS \\ From the Department of Human Ecology, University of Cambridge
}

A notable feature of the National Health Service Act is the division of administrative responsibility between the Hospital Authorities, the Local Executive Councils, and Local Health Authorities. It is now widely recognized that this division has serious disadvantages. In the discussion which follows an attempt is made to examine the historical reasons for these administrative divisions, to outline some of the present difficulties, and to suggest a possible line of action.

Der Historiker ist ein ruckwarts gekehrter Prophet, but in dealing with the growth of state medical services the historian cannot look back very far. Even so the speed of development in Britain has been quite remarkable.

\section{Historical InTRODUCTION}

Section 63 of the National Health Insurance Act of 1911 contained the remarkable provision that when sickness in any area was found to be excessive, by reason of bad housing or other injurious influences, payment of the extra amount disbursed in sickness benefit by reason of such insanitary conditions could be claimed from the local authority responsible. The motives which led to the insertion of this provision in one of the early State ventures into the field of clinical medicine are worthy of consideration. For nearly 60 years the health policy of local and central authorities in Britain had been directed towards sanitary improvement of the environment. Then, with the turn of the century, came the Boer War, the Report of the Inter-departmental Committee on Physical Deterioration (1904), and, in 1905, the appointment of a Royal Commission to enquire into the laws relating to the relief of poor persons within the United Kingdom. It is interesting to note that the members of the Commission included Beatrice Webb, Octavia Hill, George Lansbury, and Charles Booth, the Liverpool shipowner who wrote Life and Labour of the People in London (10 vols., 1892-97). The appointment of this Royal Commission on the Poor Laws in 1905 was one of the last acts of the Conservative government of the day. Then came the political landslide of 1906, with an overwhelming Liberal majority, and the emergence of a dynamic Welshman, Mr. Lloyd George. After measures relating to housing, workmen's compensation, land, and old age pensions, the Government turned its attention to national insurance against sickness and in 1911 made a direct entry into the field of curative medicine.

Hitherto experience of organized medical care had been limited to the Poor Law, the Post Office, and allied medical services, and the detested "contract practice" in which the individual doctor sold his services to provident and medical aid associations by a process of bargaining. It was against this background that Mr. Lloyd George's Bill "to provide for Insurance against Loss of Health and for the Prevention and Cure of Sickness and for Insurance against Unemployment and for purposes incidental thereto" was introduced. Any insurance scheme must be safeguarded against abuse, and anything as revolutionary as "ninepence for fourpence" might well expect to be abused. It would not be unnatural, therefore, to imagine that the question of medical certification might loom large. How much influence also the continental belief in polizeimedizin exerted is not clear, but before 1914 the influence of German opinion must have been quite powerful in Britain.

The First National Health Insurance Act, 1911 Given this background, a number of matters become more clear, including the apparent neglect of prevention, and the cavalier treatment of the medical profession at that time. To return for a moment to Section 63 of the 1911 Act, with its nine subsections and detailed instructions as to procedure, its philosophy was, in essence, punitive.

Where it is alleged that the sickness .... among insured persons ... is excessive ... and that such excess is due to the conditions or nature of employment of such persons, or to bad housing or insanitary conditions in any locality, or to an insufficient or contaminated water supply, or to the neglect on the part of any person or authority to observe or enforce the provisions of any Act relating to the health of workers in factories, workshops, mines, quarries, or other industries, or relating to public health, or the housing of the working classes ... . or to observe or enforce any public health precautions, the Commissioners or the society or committee making such allegation may send to the person or authority alleged to be in default a claim for the payment of the amount of any extra expenditure alleged to have been incurred by reason of such cause aforesaid.

Then followed the requirement that the cost of any excess of the average expectation of sickness by more than 10 per cent. should be made good by the defaulter, whether he be employer, local authority, or water company. This outlook may explain also the attitude towards the medical profession. Doctors would be necessary, it is true, to provide domiciliary medical care, but equally to ensure that insurance benefits were not abused by excessive sickness and prescribing. Club and contract practice had not, to put it mildly, achieved a very high standard of regard for the doctors. Indeed the "sixpenny doctors" of the working class areas, 
so-called because that was their standard fee, must have seemed supremely unimportant to a Chancellor bent on driving through a highly controversial measure. As Sir Clifford Allbutt, Regius Professor of Physic in the University of Cambridge, pointed out in The Times:

The Chancellor was content with an antiquated notion of medicine and of medical service. He took for granted, without enquiry, a notion built of some vague knowledge of village clubs and of the old fashioned vade mecum way of doctoring.

The determined opposition of the medical profession must have come as a surprise, but, even so, a capitation fee of $6 s$. (later increased to $9 s$.) and the threat to use whole-time practitioners as "strike breakers" if doctors did not participate in the scheme, show the level of esteem in which general practice was held by the Government only 40 years ago.

The National Health Insurance Bill became law on December 16, 1911, and came into force on July 1, 1912. A few months later a special Representative Meeting of the British Medical Association released all doctors from their pledges not to accept service. The first National Health Insurance Service dates effectively, therefore, from 1913, and in the following year came the First World War. For the next 4 years there was little time to consider such matters, and by 1918 the national outlook had changed remarkably.

1918-39.-As early as 1910, Mrs. Beatrice Webb, one of the signatories of the Minority Report on the Poor Laws (Wakefield and others, 1909) had said:

It is not even the business of the (Poor Law) medical officer to reduce sickness in his district. All that he is charged to do is to "relieve destitution in a certain specialized way", namely, to supply "medical relief" to those applicants who have braved the deterrent attitude of the Relieving Officer and satisfied him that they would otherwise be without it. From first to last, in short, the outdoor medical service of the Poor Law has no conception of the Public Health point of view (Webb, 1910).

At the end of the First World War a Departmental Committee on Local Government, with Sir Donald Maclean as chairman, stressed the multiplicity of authorities concerned with Public Assistance (they instanced that as many as nine different authorities might deal with one case) and described "the largest and most intractable case of overlapping, namely, that of the (Poor Law) Guardians as against the Health and Education Authorities." The Committee recommended the abolition of the Guardians and the merging of their Poor Law functions into those of the County and County Borough Councils (Maclean, 1926). Their proposals reached fruition in the Local Government Act of 1929. Meanwhile a most important investigation into the machinery of government had been carried out by the Haldane Committee, and it was recommended that a Ministry of Health should be established. This Ministry, with responsibility for the central oversight of Local Government, the Poor Law, and National Health Insurance, would be in an ideal position to co-ordinate the hitherto divergent medical services, and an advisory council to the new Ministry lost no time, under the chairmanship of Lord Dawson of Penn, in making recommendations for the unification of medical and allied services on a regional basis. They recognized that:

as complexity and cost of treatment increase, the number of people who can afford to pay for a full range of service diminishes. Moreover, enlightened public opinion is appreciating the fact that the home does not always offer the best hygienic conditions for dealing with serious illness.

It is interesting to scan the many papers and discussions on the advisability of a national health service which appeared at the end of the First World War. Sir William Osler was undoubtedly expressing the views of many people when he opened a discussion at the Royal Society of Medicine in 1918, on the future of the medical profession under a Ministry of National Health.

With intellectual weakness in high places the profession has too often suffered the pace to be set by organized ignorance ... Bumbledom of this type in a new Ministry of Health would only mean the exchange of the whips of Solomon for the scorpions of Rehoboam ... The war has furnished the profession with a great lever in public health matters: see to it that we have control of the handle.

His comments on the role of the general practitioner should also be noted.

Is a scheme possible in which he is a paid official of the State, yet a free agent; the executive officer of a city or county council, yet alive to the interests of science? Would he be able to tell a fussy countyo inspector "None of your blank business" without thought of the black book at Whitehall? (Osler, 1918)

Clearly the time for a national health service was not yet, and the infant Ministry of Health contented itself with the administration of existing services and the consolidation of measures to improve the environment. The National Health Insurance Service had already passed from the stage of being a novelty to that of an accepted part of life, and by the 1930s its main preoccupations were laxity of certification and prescribing, and the inadequacy of the capitation fee.

Meanwhile the County and County Borough Councils were emerging as the major authorities in the field of preventive medicine, when, as a result of the Local Government Act of 1929, they became hospital authorities also. To say that they entered this new field of curative medicine with enthusiasm is no overstatement, for the hospital activities of some of the large authorities soon overshadowed all else, and in some areas the new principle of a full-time salaried hospital service became an accomplished fact. The voluntary hospitals were not slow to recognize the danger to their own survival, but by the late 1930s the comment was beginning to be heard that "Co-ordination of hospital services in regional areas will undoubtedly take place in the near future" (P.E.P., 1937).

THE SECOND WorLd WAR.-Unfortunately the near future was full of menace, and the imminence of the Second World War introduced a new factor, Civil Defence, which was to play an unexpected part in this 
co-ordination. The country was divided into large Civil Defence Regions, each with a Regional Controller who could assume the functions of independent governor if cut off from London by bombing. In each region were miniatures of the central government departments, including the Ministry of Health, and hospitals were organized for emergency purposes on a regional basis, and subsidized for their war work from central funds. It happened that in the provinces the regional headquarters were almost invariably in a University centre. The peculiar circumstances and vulnerability of London required a special arrangement whereby the great undergraduate teaching hospitals in the central parts of London became the apical points of sectors extending out as far as 60 miles into the home counties. As will be seen later, it is from these regions and sectors that the hospital arrangements under the National Health Service have sprung. One other influence of the emergency hospital service must be mentioned here. As the war progressed it became evident that withdrawal of the government subsidy would result in severe financial strain on the hospitals, and probably bankruptcy for those which had hitherto been dependent on moneys voluntarily subscribed.

In December, 1942, the Beveridge Report recommended a comprehensive system of social security based on the maintenance of full employment, family allowances, and a national health service. Assumption B of that report called for a health service to prevent and cure disease, and also to ensure the careful certification needed to control the payment of benefit at the rates proposed. Here indeed were the issues of 1911 in a new guise (Beveridge, 1942).

Proposals under the White Paper.-After a careful review of the situation, the White Paper, "A National Health Service" (1944), proceeded to outline the scope and requirements of a comprehensive service, including the administrative structure and each of the main branches -hospital and consultant services, general practitioner service, and local clinic and other services. The special circumstances of the service in Scotland were also considered. The method of organization proposed was to make the maximum use of existing facilities and experience, with no unnecessary uprooting of established services. Local organization was to be based on County and County Borough Councils, operating in their normal local government areas where possible, but combining as joint authorities over large areas where necessary.

New hospital areas were to be created and governed by a joint authority, constituted by a combination of existing County and County Borough Councils in the area. A local consultative body, to be known as the Local Health Services Council, was to be established, to serve a similar purpose locally to that of a Central Health Services Council. Area plans were to be prepared by the local bodies for the approval of the Minister, and the joint authorities were to be free within the plan to organize the services as they wished. The voluntary hospital system was to continue side by side with the publicly provided hospitals, and voluntary hospitals would participate, if willing to do so, as autonomous and contracting agencies.
Certain national conditions, e.g. as to remuneration of nurses and appointment of consultants, were to be centrally prescribed.

General practice was also to be centrally organized, with a new Central Medical Board, with which the individual doctor was to be in contract. The assessment of local needs in general medical practice was to be the duty of the joint authority which, it will be remembered, was to be composed of local authorities. A "high place" in the scheme was to be given to a full and careful trial of the Health Centre method. "Where they (i.e. practitioners) participate in group practice in Health Centres, remuneration to be by salary or similar alternative". The Central Medical Board was to be given power to require newly-qualified doctors to give full time to the public service in their early years if necessary. The question of the sale and purchase of public medical practices in future was to be discussed more fully with the profession. Local and non-hospital clinic services were to be the responsibility of the individual County and County Borough Councils which collectively made up the joint authority. Child welfare duties were to be as much the subject of the "area plan" as any other branch of the service. New forms of service, for example dentistry and care of the eyes, were to be considered "as soon as circumstances allow".

The service was to be free to all, apart from possible charges for certain appliances, and the total cost to public funds was estimated at $£ 132$ million for England and Wales and $£ 15.8$ million for Scotland.

The White Paper, with its full explanations and careful historical survey, was clearly designed to form the basis of thorough, and indeed almost leisurely, discussion. In its insistence on retaining the local government pattern, with local responsibility for planning and execution, and indirect central control, it followed the accepted development of national services, to which the National Health Insurance Act of 1911, with its hasty flight from local government, had formed a rare exception. The White Paper was well received, but the British Medical Association found itself confronted with similar fears to those of 1911. There was the risk of loss of professional freedom and independence, the fear of a whole-time salaried service, and the danger of bureaucratic control. Above all there was the dislike of local authority control, which loomed as large in 1944 as had the fear of contractual relations with the "friendly" and "approved" societies in 1911. The Minister of Health, Mr. Willink, proved to be much more sympathetic than had Mr. Lloyd George in similar circumstances, and discussions seemed to be progressing smoothly, when, in the General Election of July, 1945, the Labour Party was returned with a large majority.

\section{The National Health Service Act 1946}

Sufficient indication of the change of tempo is given by the fact that within little more than a year a National Health Service Bill had been presented to Parliament and had become an Act, with the "appointed day" on which the new service 
was to begin some 18 months ahead. This was indeed quick work, and from now onwards little time could be spared for the niceties of discussion. That the service came into full operation on July 5, 1948, tells, better than words, of the devotion to duty and organizing ability of the lay and medical civil servants at the Ministry of Health.

One thing was abundantly clear. The reliance placed in the 1944 White Paper on the local authority machinery could no longer hold. The time factor alone would not permit of the lengthy discussions required to adjust differences, settle area boundaries, and review the plans to be submitted by the combined authorities. Apart from this the medical profession, both consultant and general practitioner, and the voluntary hospitals, including the teaching hospitals, had never hidden their dislike of local authority control. It was clear also that the Minister of Health, as the agent responsible to Parliament for the efficient working of the service as a whole, must exercise a degree of central control, including financial control, which was new. The introduction of comprehensive dental and ophthalmic services also called for new machinery.

The framework of the Act is well known, and, unlike 1911, there was a considerable body of experience on which to build. Regional organization of hospitals on a voluntary basis had already proved to be practicable before the second world war, and the Civil Defence Regions had proved their value. It was, therefore, a relatively simple matter to construct Regional Hospital Board areas with a University centre associated with each. The subdivision of the regions into Hospital Management Committee groups proved to be more difficult. It was essential to retain, as far as possible, local interest. On the other hand it would clearly be impossible to retain the governing bodies of several thousands of hospitals, and, at the same time, to provide workable groups to deal with the acute and chronic sick, infectious diseases, tuberculosis, and mental illness. Fortunately the war had left behind a body of experienced men and women who had become accustomed to thinking in terms of larger areas than those for which they had previously been responsible, and the establishment of the hospital service machinery proceeded remarkably smoothly. Consultants and specialists had already been accustomed to service on part-time and full-time contracts under the emergency hospital scheme, so that no violent transition was required. The teaching hospitals, with their associated medical schools, presented special problems, and their independence was guaranteed in England and Wales by grouping them under Boards of Governors, with direct access to the Minister, and control of $\frac{\underline{m}}{c}$ their own finances.

Meanwhile the general medical practitioners, $\stackrel{\infty}{\infty}$ on whom the bulk of the work was to fall, were becoming increasingly anxious. In place of friendly $z$ and leisurely discussions of the White Paper they $\underset{Q}{\mathscr{Q}}$ found themselves confronted with a Bill, which, all too clearly, was going to become a Statute in a s? very short time. In place of the "strike breakers"음 of 1911 was the provision that any general practitioner who did not join the service on the appointed $\frac{\bar{p}}{\bar{\sigma}}$ day forfeited his right to a share in the $£ 66$ million $\mathbb{\complement}$ set aside as compensation for the loss of the right to sell his practice. The result was aided by the ${ }_{\vec{\theta}}^{\text {s }}$ speed with which the Government proceeded. Once? an Act is passed it can only be amended by another $\overrightarrow{\vec{\omega}}$ Act, and public opinion soon tires of opposition ${ }_{\mathscr{\omega}}^{\omega}$ to a fait accompli.

Here again, well-tried administrative machinery $\stackrel{\mathbb{\Omega}}{?}$ was available. For nearly 36 years representatives. of the medical profession, and the civil servants $\omega$ responsible for the administration of National ${ }^{\circ}$ Health Insurance, had been hammering out diffi- $\supset$ culties, and it was a relatively simple matter to $\vec{c}$ change Local Insurance Committees into Executive Councils. Even the method of remuneration, by capitation fee, was to hand.

It was also administratively practicable to organige. dental services through the Local Executive Councis, but here, unlike the doctors, the dentists had feevi precedents on which to base negotiations. Their greatest bargaining assets were the facts that if they chose not to join the service they remained indis- $\mathbb{Q}$ pensable, and that the vast majority of people were $\vec{F}$ accustomed to pay for dental care. They were $\frac{0}{3}$ therefore able to insist on payment by means of $\widetilde{F}$ fee per service, a method of remuneration which hado always applied to pharmacists dispensing prescrip tions under the older service.

One unexpected complication nearly marred the smooth introduction of medical services. As the 3 . appointed day drew near it was realized that the promise of free eye services could not be imple- $₹$ mented as intended, viz. through the hospitals, for these had neither the accommodation nor the staff to meet the enormous demand anticipated. A음 supplementary ophthalmic service was therefore improvised through the Executive Councilos machinery, whereby the strain might be taken by opticians, and specially qualified ophthalmic prac-N titioners, working in their own consulting rooms. $\sigma$ The cost of this service has been much criticized but without such an arrangement the Minister's pledge of a free and comprehensive service could@ not have been fulfilled. 
Meanwhile, what of the Local Authorities who were to have been the lynch-pins of the earlier White Paper? County and County Borough Councils were now to be recognized as the major Local Health Authorities, with power to build Health Centres and to act as the connecting link between domiciliary medical care and the hospital. To this end they were to provide midwifery services, to assume full responsibility for district nursing and ambulances, to provide domestic help, and, rather vaguely, to become responsible for the care and after care of the sick, including the tuberculous and the mentally ill, in their own homes. It is possible that many of these Local Authorities had been somewhat nervous of the earlier proposals, for fusion of town and county for hospital services might well mean that the former carried the responsibility for the latter. Apart from this, many authorities might view with anxiety the possibility that submergence of one area into another for one specific purpose, viz. health, might lead to a similar process for other purposes also.

After the flurry of negotiation, preparation, and improvization, the introduction of the service on July 5, 1948, seemed almost an anticlimax. On that day the Minister of Health assumed responsibility for a service which depended, for its success, in England and Wales, on 14 Regional Hospital Boards sub-divided into 387 Hospital Management Committees; 36 Boards of Governors; 146 Local Health Authorities; and 138 Executive Councils.

\section{The Present Position}

After 5 years it can be said, quite dispassionately, that from the patient's point of view the National Health Service has worked reasonably well-at a price. How high that price is may be assessed by comparing the estimate of $£ 132,000,000$ for England and Wales in 1944, with the estimated gross cost of $£ 424,450,500$ for $1952-53$. Comparable figures for Scotland are $£ 15,800,000$ and $£ 51,364,000$.

In considering some of the problems created by the local divisions of administrative responsibility, it is necessary to remember that the State is not merely interested in medical care for its own sake. It has a number of other irons in the health and welfare fire, including housing, family allowances, national insurance, national assistance, and food subsidies. Indeed housing, good food, and the relief of poverty, are, in themselves, weapons of great potency in the prevention of disease. It is unlikely, but not impossible, that the State might at some future date be compelled to say, in effect, "We no longer need a vast medical machine. We can, and are, attacking the root causes of disease in other ways. What we now require is strict economy and rigid control of certification and sick absence."

Financial stringency, flagrant abuse of the service, incompetent local administration, or neglect of their duties by those in the service, might also render direct intervention necessary.

Until the last war, central government departments had little experience in the day-to-day running of services. Thorough consideration of local plans, with due regard to the state of the nation's finances; the spurring on of defaulters in local government and the checking of the exuberant; impartial enquiry and arbitration; and a meticulous knowledge; were their main activities. The Ministry of Health in particular, in the first 30 years of its life, established a high reputation for informal contact with those concerned with day-to-day local government, and the counsel and advice of its officials were sought and welcomed by everyone.

Partly as a result of the local sub-division of responsibilities for the health service, that role no longer holds, and the Ministry finds itself in the unwelcome position of having to interfere directly in the details of administration. The position is not made any easier by the difficulty of reconciling the venerable system of government finance by the year with the expenditure of local bodies, which should plan by decades and even, in the case of the Regional Hospital Boards, by centuries.

Turning to the local picture, it is becoming increasingly clear that many of the problems now apparent did in fact exist before. The general practitioner, for example, has always worked in comparative isolation, often under conditions which were far from ideal, and general practice has always been a "dead end" in the sense that there was no hierarchy for promotion. The curative work of the general hospitals and the preventive services of the Local Authorities were always sharply separated, except for a brief period after the passing of the Local Government Act of 1929. Even the transference of responsibility for the inpatient care of infectious disease, tuberculosis, and obstetrics from the Local Health Authority to the Hospital Service merely anticipated by a few years a change which the altered character of that work would have made inevitable.

Indeed the incalculable factor at the present time is not financial and administrative, but arises from the difficulty of foreseeing the effects of the rapidly changing pattern of disease. It seems clear that the emphasis in medical care is shifting from the hospital wards to the out-patient departments and the home, and that the social circumstances of the people, and in particular of the family as a unit, will come 
increasingly to dominate the picture. That is particularly the case with disabilities requiring prolonged care, especially in the older age groups.

Meanwhile, everything points to the need for unification of services. The interests of economy, the requirements of efficient administration, and, above all, the need to detect and prevent disease in the early stages, all call for co-ordinated effort, and it is the weakness of the health service that the present administrative divisions make combined effort difficult. Members of Regional Hospital Boards would probably be unanimous in agreeing that they are not satisfied with the progress they are making, or with their relations with the Teaching Hospitals and Hospital Management Committees. The obstacles are not entirely financial. The remoteness of the "Region", sometimes a hundred miles away from the peripheral hospitals, makes the Board member almost entirely dependent on his officers for information, and gives to the decisions of the Board a sense of detachment which is somewhat unreal. In contrast with the Regional Boards, the Hospital Management Committees have at least the satisfaction of contact with their hospitals and the privilege of grumbling at the Regional Hospital Boards when difficulties arise.

The Teaching Hospitals are perhaps the most favourably placed, for they are directly responsible to the Minister for their own groups of hospitals, and for the provision of certain regional services by agreement with the Regional Hospital Boards.

Co-ordination within the hospital service depends much on individual effort, and particularly on the readiness of chairman and officers to meet at frequent intervals. Liaison with other branches of the health service depends almost entirely on the officers, and those few members who can find time to sit on both sets of committees.

Local Executive Councils seem to be sinking rapidly into the mechanical routine which characterized their prototypes, the Local Insurance Committees. That is not surprising in the light of the enormous mass of routine work with which they have to deal. Supplementary eye-services, dental care, and the minutiae of record keeping for the domiciliary care of nearly 50 million people do not leave much time to reflect upon the wider issues, or to enquire into the progress of other branches of the service. The fact remains that it is with the Executive Council that the general practitioner, to whom so many are looking expectantly to improve the quality of medical care, is in contract.

Local Health Authorities are unique among the local bodies responsible for the administration of the health service in that they contribute 50 per cent. of the cost, by way of rates, to the services they provide for the community. It would, therefore, be surprising if they were satisfied with the present position. Their ambulances are at the beck and call of the hospital authorities and the general practitioner; their district nurses, midwives, and homehelps play an indispensable part in sharing the medical burdens of the community, and in lightening the load of domiciliary and hospital care. For the success of much of their preventive work they are dependent on the co-operation of other branches of the health service over which they have no control. It must also be remembered that County Councils and County Boroughs are responsible for many other aspects of local government, and that, despite their title under the National Health Service Act, their health activities may be secondary in importance.

\section{THE FUTURE}

All the current problems confronting the National Health Service turn upon the pivot-lack of coordination. In the interests of economy and efficiency, action should be taken before the new Boards, Committees, Councils, and Authorities develop such rigidity that remedial action becomes too difficult.

The matter cannot wait upon the emergence of $\overrightarrow{0}$ all-purpose authorities, for, given unanimity ob opinion (a large assumption), their creation would not be practicable within less than 5 years. Everyone agrees that unification of administration must come; and the establishment of a cadre of highly trained professional administrators, medical and lay, interchangeable between central and local administration, would go far to remedy the present defects in the health service. An important part of the training of such men would be the recognition that the service with which they deal is not, and never will be, static, and that it, like the individual men and women who compose the State and for whom it exists, has a more than material value.

\footnotetext{
REFERENCES

Beveridge, W. (1942). "Social Insurance and Allied Services". H.M.S.O., London.

Booth, C. (1892-97). "Life and Labour of the People in London", 10 vols; 1902, 3rd ed., 17 vols. Macmillan, London.

Maclean, D. (1926). "Local Government Committee. Report on transfer of functions of Poor Law authorities in England and Wales", Cd. 8917. H.M.S.O., London.

Ministry of Health and Department of Health for Scotland (1944). "A National Health Service", (White Paper) Cmd. 6502. H.M.S.O. London.

Osler, W. (1918). Lancet, 1, 804.

P.E.P. (Political and Economic Planning) (1937). "Report on the British Health Services", p. 264.

"Report of the Inter-departmental Committee on Physical Deterioration", Cd. 2175 (1904). H.M.S.O., London.

Wakefield, H. R., Chandler, F., Lansbury, G., and Webb, B. (1909). "Royal Commission on the Poor Laws: Minority Report", p. 34.

Webb, B. (1910). "The State and the Doctor", p. 84. Quoted by Williams (1932).

Williams, J. H. H. (1932). "A Century of Public Health in Britain, 1832-1929". Black, London.
} 